\title{
Peer Promotions as a Method to Identify Quality Content
}

\author{
Bjorn Levi Gunnarsson and Richard Alterman \\ Brandeis University, USA \\ bjornlevi@cs.brandeis.edu
}

\begin{abstract}
Promoting blog content is a social activity - a means of communicating one student's appreciation of another student's work. This article explores the feasibility of using student promotions of content, in a blogosphere, to identify quality content, and implications for students and instructors. We show that students actively and voluntarily promote content, identify quality material with considerable accuracy, and use promotion data to select what to read. We explore the benefits of knowing which students are good and poor predictors of quality content, and what instructors can do with this information in terms of feedback and guidance.
\end{abstract}

Keywords: Blogging, social blogging, liking, promoting, assessment, quality content, learning analytics, knowledge community, social recommendation, recommender system

\section{INTRODUCTION}

The traditional classroom is changing, with devices (laptop, smartphone, et cetera) that access the Internet, connecting the classroom to the larger world. For some classes, all communication is online, making the classroom completely digital. Other classes are blended to some degree or another - part classroom, part online. Using digital communication is relatively new in learning. Neither learners nor instructors can be assumed to pick up this new learning tool automatically and fully understand its possibilities or use it effectively. To complicate matters further, the technology is rapidly changing; new applications are constantly being created and devices upgraded. What does not change is that, with each day, the integration of learning with digital technologies is further advanced. This marriage produces significant amounts of data. This is where the field of learning analytics comes into play, applying analytical methods to the content created by the learners online (Siemens, 2011).

In class, the instructor has face-to-face access to her students. Online, students and instructors become entities of the Internet, where their presentation of self is constrained by the selected mode of communication. Common communication methods are email, forum posts, blog posts, and chat rooms (possibly with audio and video). These methods of communication have different features than face-toface communication; each of them providing alternate constraints and opportunities for contributing to a learning discourse (e.g., Baker, Hansen, Joiner, \& Traum, 1999). Each contribution can be bookmarked, shared, liked, read multiple times, tagged, referenced, and quoted. Within the bounds of a semesterlength class of students, the creation of this kind of information is a sign of social activity among students. Making visible this kind of social data to the entire class provides important peer feedback and recognition; it also potentially creates valuable data for learning analytics.

This article will show that social data is a significant element in loosely coupled online collaborative environments, beneficial to both students and instructors. We will focus on one sort of social data: promotions - one student anonymously and subjectively assessing the quality of another student's work by clicking a button. The promotion activity can take alternate forms; for example, liking or giving a 
(2014). Peer Promotions as a Method to Identify Quality Content. Journal of Learning Analytics, 1(2), 126-150.

merit badge. We show that the data can be used to solve significant problems for both students and instructors.

The field of learning analytics applies methodological scrutiny to learner-created content, such as the data created through promotions. In online learning settings, collecting data is easy; all activities can be saved for analysis. It would not be so easy to get the same data from a classroom discussion. This easy access to data has created the field of learning analytics and the data has inspired much new research. Creating sense-making visualizations for instructors and administrators (Dawson, 2009), exploring knowledge building in online social settings (Ferguson \& Buckingham Shum, 2012), and data mining institution-sized data sets (Arnold, 2010; Smolin \& Budakov, 2012) are examples of work done in this field.

In a technology-mediated environment, the intersection of the learning framework and the analytic methods form a middle space (Suthers \& Verbert, 2013). An underlying theory of learning is a significant element of the foundation of any online learning environment: it provides both a rationale for the design of the learning environment, including the scaffolding, and a basis for analysis (p. 2). In other words, learning theory motivates the invention of technology, the use of the technology produces data, the analysis of the data can suggest methods to fix problems and enhance the learning experience for any (or all) of the stakeholders, most notably either the students or the instructor. These enhancements and solutions can then again impact the theory and produce another cycle of new problems and solutions.

Contrast, for example, the underlying assumptions of two alternate projects to support student online learning. In one case, the VirtualMathTeam project (Stahl, 2009), students work together online, in small groups, at the same time from different locations in a partial joint-focus space; learning for relatively short periods of time, by negotiating meaning in the social world (Stahl, Koschmann, \& Suthers, 2006). In a contrasting case, students collaborate in a blogging environment throughout the semester - working together in a loosely coordinated fashion at different times and different locations - creating and distributing knowledge, and collaboratively building skills (Alterman \& Larusson, 2013). Because the learning framework for these two examples is different, the middle space will be different. The analytical methods might have some overlap, but some of the goals, results, and conclusions will be radically different.

The research reported on in this article analyzes learner-created content in two classes (107 and 50 students). The classes were both blended courses, with lectures twice per week, and ongoing participation in an online knowledge community as a requirement. While the amount of data is not as much as for institution-sized data sets or MOOCs (massively open online courses), the data is still significant because it represents the normal conditions for many learning environments. Despite the limits of the dataset size, important results can nevertheless be obtained.

In both classes presented, each as a case study, the students blogged throughout the semester, collectively producing much content each week; in one of the classes, students produced roughly 300 contributions per week totalling around 100,000 words, or ten times the length of this article! Without some learning analytic intervention, this amount of raw material for the students to navigate, and for the instructor to assess, is overwhelming.

This article explores the value of promotions in a collaborative online learning environment in a blended course. The students work in a loosely coordinated fashion - they work in a blogosphere - producing 
large amounts of content in a student-owned space. At least two issues emerge because of the number of posts; assessment can become overwhelming for the instructor, and finding the relevant content for the students. Promotions, as a feature, have the virtue of being peer-created content that does not increase the instructor's workload to produce. The issue concerns the value of promotion data: Does the promotion activity identify high quality with minimal instructor involvement?

\section{PROMOTIONS AS A SOCIAL ACTIVITY}

In a traditional classroom, a student typically only has access to verified high quality content like books, articles, and lectures supplied by the instructor. Online there might be videos, more articles, and tutorials by other professionals. Other sources of content are peers, but here the quality of the content is mixed. Offline peer content can be produced by study groups, group projects, and classroom discussions. Online peer content can be produced in a knowledge community that uses technologies to enable content creation and distribution online (e.g., wikis, blogs, forums, and chats). The higher quality peer-created content can serve as a valuable resource for learning, but traditionally separating the good from the bad is the province of the instructor, which, for large amounts of content, makes it prohibitively time-consuming and thus a prime target for learning analytics.

Giving students access to each other's contributions is the basis for a knowledge community (Scardamalia \& Bereiter, 1994), with each contribution representing a different, but valid, viewpoint that provides scaffolding for others to build upon and improve. Individual perspectives are shared, developed (Stahl, 2003), and composed (Suthers, 2006). Different contributions and examples on the same subject are multiple representations, which are valuable for learning (Ainsworth, 2006), and can lead to higher order thinking (Ellison \& Wu, 2008; Philip \& Nicholls, 2009). Depending on the technology that mediates peer collaboration, there will be different benefits. For example, a blogosphere is especially valuable as a resource for co-reflection among the students, which is very helpful for learning (Deng \& Yuen, 2011).

Students produce content of mixed quality; ideally, the best content is foregrounded in some way. One solution is to have the instructor and graders identify the quality content for the rest of the class. However, as the size of the class increases, the cost of finding good content, without any automated assistance, becomes quite labour intensive - perhaps prohibitively so. An alternate solution is to have students themselves locate and label important content as they read. In the studies presented in this paper, students can attach likes and badges to each other's contributions. Collectively these features can be called promotions: the reader considers the content noteworthy and wants to label it publicly as such for the community. If the social data is reliable, quality examples will be identified, which can subsequently be used as a basis for comparison and self-assessment by other students. This scheme potentially makes the large quantity of content being produced more manageable for the students. It also can provide valuable feedback, as it potentially both recognizes and confirms the value of an individual contribution.

In this article, we present a social feature (promotions) to filter for quality content. The purpose of this feature is to have students collectively identify content that is noteworthy and helpful when creating new material. These promotions are anonymous and persistent, making them very useful for later exploration by assisting navigation. The instructor can also use the promotions to classify students based on their reading and writing abilities. This leads to a more accurate sorting of the quality content, beneficial for both the students and the instructor. The main result is that analysis of the learner-created 
content verifies that student promotions can be used as a basis for identifying high quality material in the blogosphere.

The findings are several-fold: 1 ) students actively promote content; 2) promoted content tends to be of higher quality than non-promoted content; 3 ) students use the promotion data to navigate; 4) some students are reliably better at assessing quality than others, and they can be identified. Findings like these confirm the value of promotions as a learning analytic metric, adding a new dimension to the middle space generated by students engaged in loosely coordinated learning activities. The feature is simple to use, and easy to implement and understand.

\section{BACKGROUND}

The web has changed the way we do many things, Web 2.0 even more so (O'Reilly, 2007). It all began with a proposal on how to manage information more accurately, how to prevent the loss of information (Berners-Lee, 1989). This has direct impact on how the web is engineered and how useful it can be for education, which is in the business of creating and distributing information. Very soon researchers, educators, and science fiction writers started thinking about accessing human "knowledge" with notebook-sized computers (Kay, 1991) and creating computer supported (intentional) learning environments (CSILE) (Scardamalia \& Bereiter, 1994).

One such learning environment is blogs, which are widely used for various educational purposes (Deng \& Yuen, 2011; Ducate \& Lomicka, 2005; Williams \& Jacobs, 2004). Frequently blogs are used as an open journal (Zagal \& Bruckman, 2007) or a tool of reflection (Deng \& Yuen, 2011; Nardi, Schiano, Gumbrecht, \& Swartz, 2004). Student blogging has been reported to have positive effects on, for example, on the following: higher order thinking skills (Ellison \& Wu, 2008; Philip \& Nicholls, 2009); knowledge sharing and reflection (Du \& Wagner, 2006; Hong, 2008; Luehmann \& MacBride, 2009); the learning process beyond the classroom (Ferdig \& Trammell, 2004); sense of ownership (Hong, 2008); sense of community as measured by the community dimension (Deng \& Yuen, 2011); and identity development (Luehmann, 2008). Some have cautioned that just having students blog does not automatically guarantee positive learning outcomes (Divitini, Haugalokken, \& Morken, 2005; Krause, 2004).

There are two basic types of blogs: a community blog where the whole class posts to a single blog or a collection of individual, student-owned blogs. In the case studies presented in this article, each student has her individual blog within a single closed community, thus combining the two basic types. When viewing the front page of the class, it looks like a community blog where posts by all members are listed in reverse chronological order - this creates a sense of community. Alternately, the blogosphere can be accessed through the contributions of a single student: each student has her own profile page that lists all of her posts - this enables students to develop their identity and feel a sense of individual ownership.

When we say community, we must recognize the importance of the social aspect. Knowledge creation as a social product (Scardamalia \& Bereiter, 2006; Scardamalia, Bransford, Kozma, \& Quellmalz, 2012) is complicated and vast; it bounds both formal and informal learning environments as well as networks and communities of people. Ferguson and Buckingham Shum propose five categories of social analytics: 1) social network analytics, 2) discourse analytics, 3) content analytics, 4) disposition analytics, and 5) context analytics. Content analytics is classified as being "a broad heading for various automated methods used to examine, index, and filter online media assets for learners" (Ferguson \& Buckingham 
Shum, 2012). In this article, we examine learner-created promotions (i.e., content analytics) and propose that they can be used to filter for high quality content in a blogosphere.

Given the popularity of educational blogs, understanding some of the social features involved will have significant value. A knowledge-building community is not simply the text of posts and comments; there is so much valuable data for all involved in the learning process. Exploring how many posts students read has been found to be informative (Gunnarsson \& Alterman, 2012). Meta-data (i.e., promotions, tags, et cetera) produced by the students can increase awareness and involvement. Counting comments, counting external links, login data, load time, and many other features (as listed in Kargar \& Azimzadeh, 2009) can all help make sense of the online community.

Blogging is a simple activity requiring little technical skill (click buttons to write, publish, browse, read, or comment). Blogs are versatile and widely used for various purposes (Nardi et al., 2004). Different methods of measuring content quality have been applied to blogs (Huang, Cheng, \& Huang, 2009; Ulicny, Baclawski, \& Magnus, 2007), such as search and clustering algorithms (Ulicny et al., 2007); voting and automated methods based on various quality measures (Kargar \& Azimzadeh, 2009); classification of different types of blog posts using machine learning techniques ( $\mathrm{Ni}, \mathrm{Xue}$, Ling, Yu, \& Yang, 2007); and using natural language processing (Rubin \& Liddy, 2006). New features have been added to blogs attempting to enhance learning such as dynamic learning maps (Wang, Huang, Jeng, \& Wang, 2008) and awareness graphs (Ferguson, Buckingham Shum, \& Deakin Crick, 2011).

The blogosphere gives students the opportunity to collaborate outside of class in a loosely coordinated fashion (Alterman \& Larusson, 2013). Multiple conversations emerge on a single topic, enabling greater coverage and diversity with reduced coordination costs. Students publish to the rest of the class, providing multiple examples of work in a commons of information (Benkler \& Nissenbaum, 2006; Bruckman, 1998; Scardamalia \& Bereiter, 1994). Each student has her own blog but the collection of individual blogs make up the knowledge community. The collaborative effort of the students is not jointly focused to solve a particular problem but is rather a loosely coordinated collection of representations that together form a collective solution. Multiple conversations emerge from a single topic without the need to converge. These conversations persist over the course of the semester giving students a variety of resources to reference and refine.

Blogging enables students to work together, even though they participate at different times from different places. Together the students explore the solution space more widely in their individual posts but each contribution is examined less closely. In a joint focus space, where students discuss each contribution as it is made, that mechanic of working together limits the number of contributions that can be considered, but increases the warranty of contributions that survive in the problem space. With a loosely coupled learning activity, like blogging, the situation is reversed. Larger numbers of contributions become a part of a persistent content space and additional work is required to provide warranties that rate the quality of a contribution. Promotions can potentially provide a crowd-sourcing solution to this problem: students' subjective assessments of high quality content can provisionally provide a costeffective mechanism for creating warranties and input into a recommender system (Lü et al., 2012).

\section{TWO CASE STUDIES}

The two cases for data analysis come from two classes: the first of 107 students and the second of 50 students. There was a mix of undergraduate and master's students in both courses. The first class had 
weekly writing assignments completed in a class blogging environment. There were three kinds of assignments: 1 ) to write an editorial based on a book read in class, 2) to write a review of the book, and 3) to write a reflection on cross-cutting themes between the assigned readings. Students were encouraged to post drafts before the deadline, so they could collaborate as they completed their work on each assignment. For this class, students could promote by giving a like or by assigning merit badges for various exemplary features of a post.

We used data collected from the second class (50 students) to confirm the key results of the first study; despite a smaller set of promotion types, the key results were verified. In the second class, the students had weekly assignments where they practiced the methods and techniques taught in the class. Again, students could post drafts and revise their own homework up until the deadline. For this class, there were no merit badges, but the students could give anonymous likes to the work of other students.

\section{CASE STUDY ONE: WEEKLY WRITING ASSIGNMENTS IN AN INTERNET \& SOCIETY COURSE}

The first case study was done in a class on Internet \& Society (I\&S). During the semester, students read four books on the social impact of the Internet and had weekly writing assignments to be completed in the blogosphere. Each student had her own blog, composed of multiple posts she authored. Students were encouraged to leverage each other's work; to read freely throughout the semester in the blogosphere, joining conversations that struck their interest; and to use the blogosphere as a resource to improve their own posts. Just browsing in the blogosphere and looking at other students' work has tremendous educational value. While working on an assignment, reviewing the posted work of other students was allowed. It was also permissible to revise posts, and revise again, up until the deadline. In this manner, the blogosphere is a platform for peer tutoring, peer assessment, and collaborative learning (Topping, 2005). In addition to the blog assignments, the students also had weekly assignments to provide peer comments and assessment "officially" on the posts of other students.

For each book, the students had to write both an editorial post and a book review post. Each post was required to be between 600-750 words in length; in practice, many of the posts were longer than that. The editorials required the student to review an issue raised by the book and then take a position, either expanding on the argument of the book with examples or presenting counterarguments. Each review explicated the central argument of the entire book. Students explained the key points, referenced (at least three) editorial posts of fellow students as support for their analysis, provided additional examples, and argued for (or against) the core argument of the book. In the latter part of the semester, students were required to write three reflections synthesizing material from two or more books and referenced posts written on the books. A requirement for these reflections was to reference at least three editorials or reviews written by other students. The same comment and assessment process also applied to the reflections.

Each student was required to write two comments and give two peer assessments each week (400 words in total). After the assignment due date, two posts were randomly assigned to each student on which she would officially comment, and another two other posts for which she was responsible for giving a peer assessment using a 3-point questionnaire form. The peer comment was posted under the student's user name but the peer assessment was anonymous. The comment was public but only the author of the post had access to the results of the questionnaire; comments and assessments were to be both "thoughtful" and "judicious." To ensure quality, both forms of feedback were evaluated by a grader. 
Students were also encouraged to make additional comments, respond to comments on their own posts, and anonymously promote posts by giving them likes and badges. The additional activities were not directly graded, no feedback was given about promotions being good or bad, but promotions were considered part of the participation metric in the overall grade.

Because of the specific requirements of the blogging assignment, the students got plenty of feedback on their contributions to the blogosphere. The comments and peer assessments produced by other students were one form of feedback. Grades and publicly displayed gold stars for excellent work, given by the TAs, were a second form of feedback, and the peer promotions (badges and likes) were a third kind of feedback.

The course assignments were designed to be used as reference material later in the semester. Students not only had reason to review their peer work in the current assignment but, because of the design of the review and reflection assignments, they also had a reason to review past assignments. This potentially meant each assignment was more valuable because it was not just deliver and forget; it had future value for the student and the class as a whole.

\subsection{What is the Issue?}

Students produced a huge amount of text (600-750 words) on a weekly basis. The official comments on the work of two other students after the deadline for the post were a minimum of 200 words. For a class of roughly 100 students, this meant 300 contributions per week (one post and two comments per student). Or to put it differently, each student was producing 1000 words per week, which meant a minimum of 100,000 words per week produced by the entire class.

Because students were collaborating as they wrote each post, the merits of finding better quality material are obvious. High quality content, by definition, is easier to understand, easier to learn from, and easier to expand upon. There was also additional value in peer promotions, the results were used to gauge the reading and writing ability of the student. Both the reviews and reflections required students to cross-reference other posts, meaning that the writer paraphrases or quotes from another student's post and provides a hyperlink to it. The reviews were required to refer to at least three editorials. The reflections were required to refer to three other posts, either reviews or editorials. Additionally, although not required, many students included cross-references in their editorials.

Two factors contribute to the selection of a post to cross-reference: 1) the student needs to find a post relevant to her argument in her own post (the search mechanisms provided by the blogging environment supported this activity); 2) even after the initial search, many posts are relevant and useful to a student's post - ideally, the student wants to find not just a relevant post, but also a good one. Thus, finding good content was important while writing any of the three types of posts. Do student promotions provided effective feedback to guide the selection of good content? The results indicate that they do.

For the instructor, the enormous amount of content being created is problematic for a number reasons. The advantage of a student-owned space is that it helps students to open up and explore the material among their peers. Ideally, some guidance is provided to help students orient themselves towards the better content in the blogosphere, thus improving their overall peer discussion. Given the amount of material, depending on the instructor to provide all of this guidance is problematic because the work it would entail is enormous. For example, one mechanism for the instructor to provide direction is to give 
gold stars to the best work for each assignment. The gold stars come after the completion of the assignment, providing a standard to which all students in the class can compare themselves. But identifying the gold star material in a class of $100+$ students is not a trivial task. Can the analysis of the peer activity data, the promotions of the students, provide some of this guidance? The results from this study say yes.

\subsection{More about the Class: Grading}

There were six graders for the I\&S class; this amount of grading support cannot be assumed for a typical class. Posts were graded differently than comments and peer assessments. Three graduate students graded the posts; a third of the posts were randomly assigned to each of the graders after the due date of each homework assignment. The grading was done by filling out a 6-item questionnaire. Each homework type (editorial, review, and reflection) had different questions. For example, the grading questionnaire for an editorial post was:

1. The issue is clearly explained.

2. The opinion is interesting and substantial.

3. The references are relevant to the argument.

4. The post is well written.

5. The post demonstrates understanding of the subject of the book.

6. Overall grade for this post?

Each question could be given a value from 0 to 3 . Zero means that part was "not completed" (for example no references in the post would yield a 0 for that part of the questionnaire), 1 is "not good," 2 is "good work," and 3 "exceeds expectations." Students were told to expect a 2 to be a good passing grade. Grading was done inside the blogosphere but in a special grading view where only the questionnaire and the text of the blog post were visible. The graders could not see the blog post's comments, likes, or badges without intentionally browsing to that blog post in the standard view. This "blind review" was done to minimize any bias the post's comments and promotions could have on the grader.

The comments were graded by three undergraduate students. The comment and peer review forms were simpler - just asking if the comment or peer review met expectations - the graders could give a 0 for "not completed," 1 for "not good" and 2 for "good work." Grading did not overlap between graders within the same assignment. Posts, however, were randomly assigned to a grader so that over the semester each student had assignments graded by all graders.

Periodically the head TA would give out gold stars to the high quality posts for each assignment. The grades of gold star posts varied a bit, although all were of high quality (graded from 14 to 18) some provided exceptional examples even if the post as a whole did not warrant the highest possible grade. The purpose of the gold stars was to identify high quality content "officially" for the community as a whole so that students could compare it to their own. Sometimes the gold stars were given out shortly after the assignment due date and at other times much later. A total of 80 gold stars were given throughout the semester.

The average number of person-hours spent grading each week was 31 hours; over the entire semester, the total was roughly 350 hours. For each assignment, the instructor would meet weekly with all six graders to give an overview of how to grade the most recent assignment. These meetings typically lasted 
around an hour (totalling ten person hours per week). From interviews with the graduate graders (who graded the posts), we learned that the average time spent on grading posts was around four hours per grader (twelve hours per week total). The average time spent grading comments and assessments was about three hours per grader (nine hours per week total). Clearly, this is an enormous amount of work and many courses will not have sufficient resources to commit to this level of grading. Being able to simplify some of the process of identifying good content, providing feedback, and evaluating student work would have tremendous value.

\subsection{More about the Class: The Technology}

The blogging environment was developed at Brandeis University over a number of years; the current version is a recent rebuild by the first author of this paper, which has already been used in several classes. We refer to this type of blogging as social blogging because students blog collaboratively, as individuals within a group blogging system, and the blog includes several social features, like promotions.

Students may browse content in the blogosphere using several different views. Most of the time, students would start a session by viewing the front page, which lists of the most recent posts. From there, a student could switch to an alternate view. Examples of available views include the following: all posts on a specific book, all posts by an individual student, all posts with a specific type of promotion, all posts receiving a gold star from the TA, and all posts the student had commented upon. It is also possible to do a keyword search to retrieve a list of all posts containing the search term. Regardless of the view, posts are always listed in reverse chronological order, with the most recently added posts at the top of the page. For each post in any view, its entry includes the name of the author of the post, the title of the post, the type of post (editorial, review, or reflection), the book(s) the post discussed, the number of comments the post had accrued, and the number of promotions it had received. Students could preview the first paragraph of a post by hovering over its title; they could then click on the title to view the post in its entirety, as well as any comments made on the post.

\subsection{Student Promotions in the Blogosphere}

While browsing in the blogosphere, students could promote posts by assigning them merit badges and likes. Liking a post means exactly that - the student supposedly liked it. Merit badges are a more specific type of a post promotion. Instead of clicking a button to say you like the post, you can click a button to say that you liked it because it was, for example, "nicely written." Students could only give each post one like and one badge of each type. Each student could, in practice, give a post one like and six different badges. The badges were:

- Good example: The post contains an interesting example or case as a basis for its argument.

- Good question: The post raises an interesting issue.

- Nicely written: The post is well written.

- Good argument: The post makes a persuasive argument.

- Good references: The references are interesting and relevant.

- Good summary: The post provides an accurate and succinct summary of an issue or the book.

There was incentive to identify high quality posts in the blogosphere - earlier posts were referenced in later assignments. By finding high quality posts that clearly explained a topic in one of the books, the student could more easily build her argument when reviewing or reflecting on the central issue of the book. Reading poor quality posts would not be as helpful. Searching for good quality posts takes work, 
but also depends on a student's ability to identify what is a good post. The data will show that not all students were good at assessing quality.

\subsection{Evaluation: The Data}

The last assignment of the semester is left out of the data, as it is an outlier. Student participation in the last assignment was very different from the previous ten. This is most likely due to the fact that the semester was ending and students were busy finishing up their work in many classes.

The data compiles the promotion statistics of 92 students. The 15 students filtered out did not participate fully in the blogosphere and there were several possible reasons for excluding their data: only completing the first one or two of the 11 assignments, incomplete assignments, not participating in the blogosphere, or finishing most of the work after the end of the semester. For each of these students, their data was removed from the set.

\subsection{Evaluation: Overview}

All of the posts were graded, during the semester, on a scale of 0 to 18 . For the purposes of this evaluation, posts with a score of 14 to 18 are high quality posts, 9 to 13 are average quality posts, and below 9 are poor. An outline of the evidence presented in the evaluation is shown in the Summary of Evaluation below. The utility of student promotions depends on several factors. For this scheme to work, students must actively promote during the semester, and the content they promote must in general be of high quality (evaluations 1\&2). This information is useful for students only if they use promotions to help navigate in the blogosphere (evaluation 3). If promotions can be used to identify better content, they can potentially be used for highlighting content - as support or replacement for the identification of gold star material - and therefore, improving the reliability of promotions can greatly improve their functionality. How can this be done? One way is to separate the good promoters from the bad promoters. The evaluation presented explores whether promoters whose evaluations are reliable can be differentiated from those whose evaluations are more random (evaluation 4). The evaluation also explores how promotions and the content quality changes during the semester (evaluation 5).

\subsubsection{Summary of Evaluation}

Evaluation 1. Do students promote posts as they read in the blogosphere?

Evaluation 2. Are the promoted posts, on average, of higher quality than the average blogosphere post?

Evaluation 3. Do students use promotions to navigate in the blogosphere?

Evaluation 4. Are some students more reliable evaluators of quality content than others?

Evaluation 5. Promotions and post quality during the semester.

The data shows that students produce many promotions, many posts do not receive promotions, and the posts that receive promotions vary in how many promotions they receive. The average grade of promoted posts is significantly ( $p$-value $<2.2 \mathrm{e}-16$ ) higher than that of non-promoted posts. Some students were better than others at promoting, and as the semester progressed, the quality of the content in the blogosphere increased.

\subsection{Evaluation 1: Promoting Content}

Under what conditions are student promotions useful? If the promotion feature is rarely used, they risk getting lost. If there promotions are too many, they become meaningless. For the entire class, $89.7 \%$ of 
students used the promotion feature at least once. In the first assignment, many students used the feature, but the number of students who promoted declined in later assignments. During the whole semester, the average student promoted 6.77 posts from 3.75 assignments. For each assignment, 37.8\% (an even third if the first assignment is excluded) of the students gave out a promotion. During the first assignment $78.2 \%$ of students gave a promotion and during other assignments between $50 \%$ and $16.3 \%$ (in the last assignment) gave promotions.

The proportion of the number of promotions per assignment follows a similar trend, each of the ten assignments received, on average, $10 \%$ ( $8.5 \%$ excluding the first assignment) of the total number of promotions given throughout the semester. The first assignment received $23.7 \%$ of all promotions with other assignments getting between $11.9 \%$ and $4.9 \%$.

Around $80 \%$ of promotions were made before the official commenting period ended (and thus before the assignment was graded). This makes them very useful while students are working on the same assignment and helpful when students are searching for quality content to reference in later assignments. Quite a few promotions were available before the assignment deadline, giving students access to higher quality content, on average, to help understand the problem. Later, when reviewing prior assignments, the search function can be used to find relevant content and then the promotions quickly indicate the best posts.

Later assignments were less likely to be used as reference material because they were designed as reflections on the first eight assignments. Students are also busy with exams at the end of the semester. Both of these aspects could have a reducing effect on promotions. Despite the outliers, the first and last assignments, we believe both the rate and number of promotions given throughout the semester were good.

\subsection{Evaluation 2: Quality of Promoted Content}

This evaluation seeks to answer the core question of this article: Does the promotion activity identify high quality with minimal instructor involvement? In order to answer this question we ask what was the quality, in terms of grades, of the posts that received a promotion? We answer this question in three parts:

- Higher quality posts got more promotions. (See: Number of promotions per post)

- Higher quality posts were more likely to be promoted. (See: Promotion hit rate)

- All types of promotions were useful (See: Different types of promotions)

If higher quality posts get more promotions and if higher quality posts are more likely to be promoted, then the subset of promoted posts is of higher quality. How much we answer in the following evaluations.

\subsubsection{Number of promotions per post}

Figure 1 shows the total number of promoted posts and the total number of posts not promoted, both grouped by grade. It also shows the number of total promotions for posts of each grade. The data shows an interesting increase in the number of promotions on content with high grades (see the shaded region in Figure 1). In other words, all posts can receive promotions, but posts with high grades get significantly more promotions than posts with a lower grade $(p$-value $=0.002045)$ (see Figure 2$)$. 
(2014). Peer Promotions as a Method to Identify Quality Content. Journal of Learning Analytics, 1(2), 126-150.

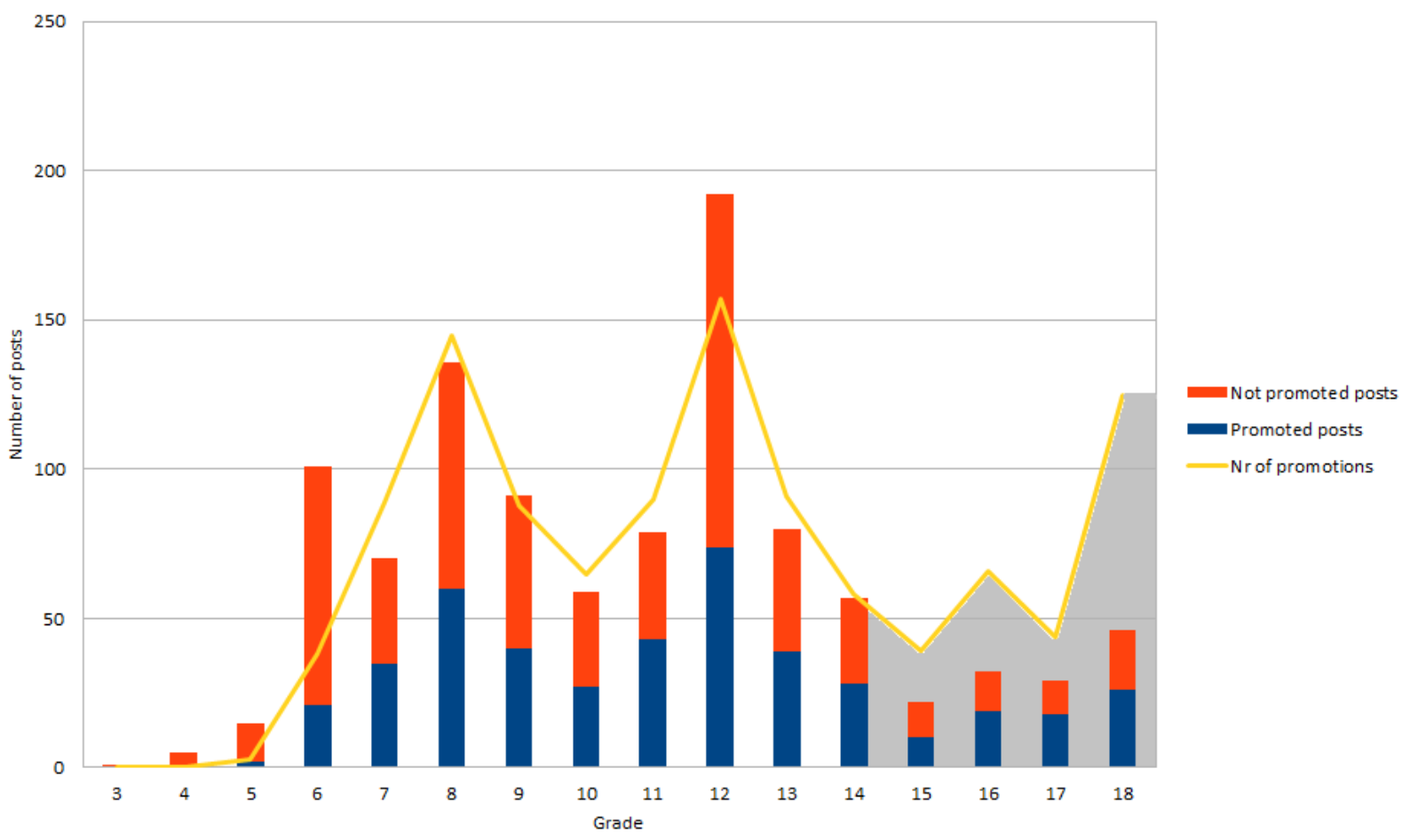

Figure 1. Number of posts and promotions per grade

Post grade to promotions ratio

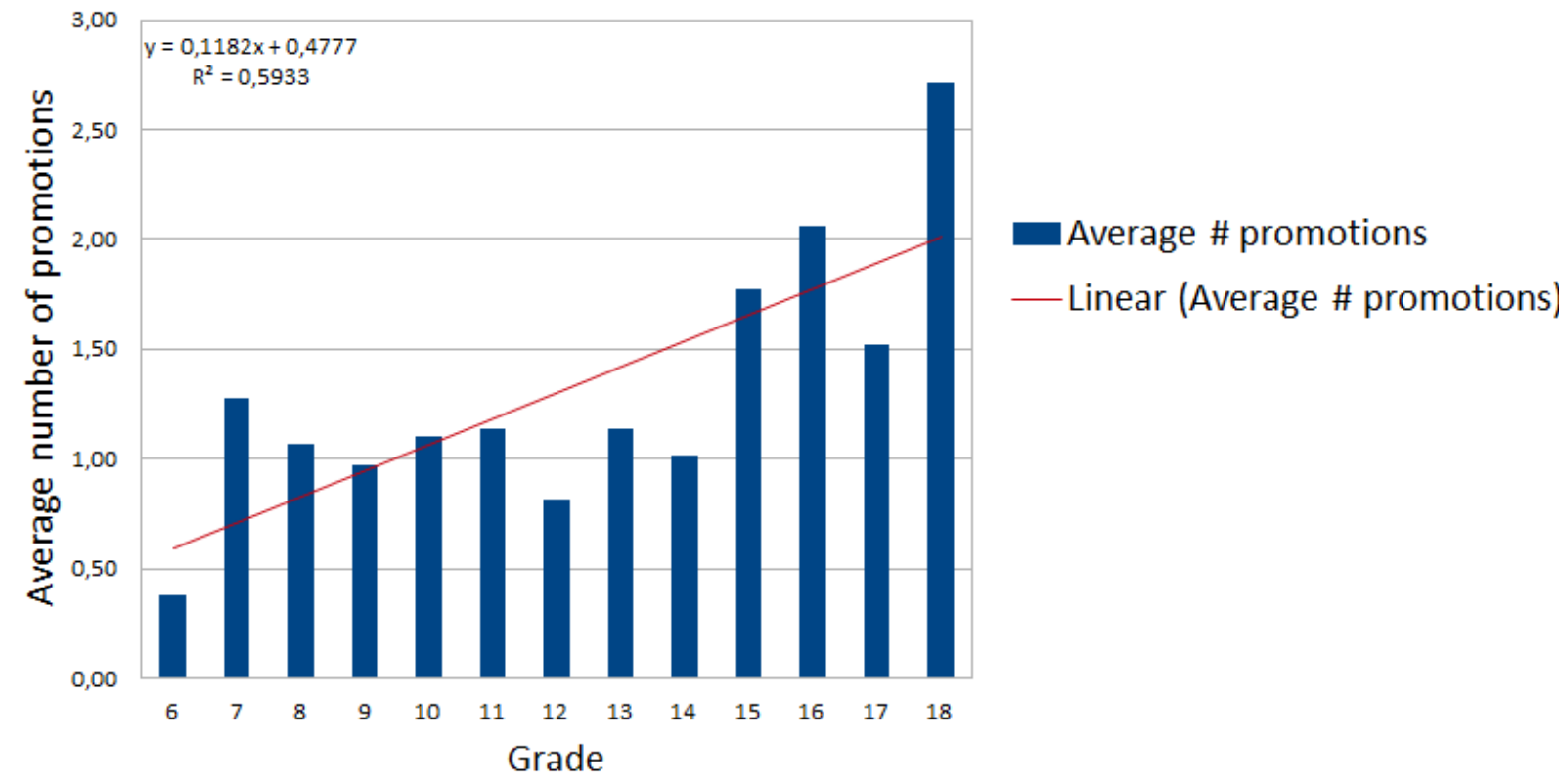

Figure 2. Average number of promotions per grade 
(2014). Peer Promotions as a Method to Identify Quality Content. Journal of Learning Analytics, 1(2), 126-150.

\subsubsection{Promotion hit rate}

Were high quality posts more likely to be promoted than lower quality posts? Only $36.2 \%$ of all low quality posts (graded 8 or lower) were promoted. This means low quality posts have a $36.2 \%$ hit rate. The hit rate increased to $47.3 \%$ for posts of average grade (graded between 9 and 13), and high quality posts (graded 14 or higher) had a hit rate of $54.3 \%$. The difference in hit rate average is only significant between poor and high ( $p$-value $=0.033$ ) but the distinction between poor and average is higher ( $p$-value 0.11 ) than between average and high ( $p$-value $=0.2165$ ); students seem to identify average posts over poor posts more easily than high quality posts over average quality posts.

Comparing the average grade of posts with and without a promotion paints a clearer picture. The distribution of promotions between high and low quality posts is significantly different (see below), indicating that students can, on average, identify high quality peer content.

\subsubsection{Different types of promotions}

As mentioned before, we named the activity of liking and giving a badge as promoting. We analyzed the data for each type of promotion (see Figure 3 ). The average grade for all posts during the semester was 10.7 (see horizontal line for average class grade). With one exception, all types of promoted content had higher grades than the average class grade.

There were six different types of promoted posts in the blogosphere: 1) posts that were both liked and badged; 2) posts that were liked and could have badges too, 3) posts that were liked and had no badges, 4) posts that got badged and could also have likes; 5) posts that were only badged and had no likes; and 6) posts that received no likes or badges. Comparing the five groups that had promotions to the group

(6) that had no promotions:

1. Posts that had $1+$ likes and $1+$ badges had a significantly higher grade ( $p$-value $<2.2 e-16)$.

2. Posts that had $1+$ likes and $0+$ badges had a significantly higher grade ( $p$-value $<2.2 e-16)$.

3. Posts that had $1+$ likes and 0 badges had significantly higher grades ( $p$-value $=8.181 \mathrm{e}-09$ ).

4. Posts that had $0+$ likes and $1+$ badges had significantly higher grades ( $p$-value $=0.006887$ ).

5. Posts that 0 likes and +1 badges did not have significantly higher grades ( $p$-value $=0.3264$ ).

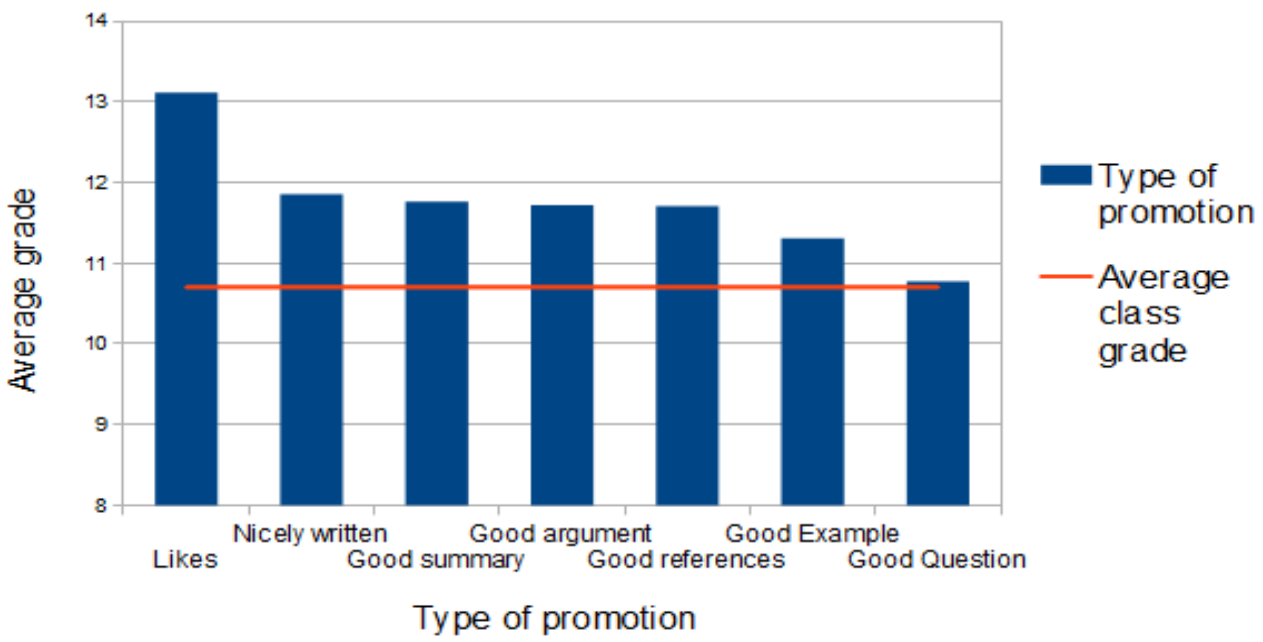

Figure 3. Average grade per type of promotion 
(2014). Peer Promotions as a Method to Identify Quality Content. Journal of Learning Analytics, 1(2), $126-150$.

Badges do not add anything to the predictive power of likes, statistically. The numbers, however, are different for each badge, as shown in Figure 3. Badges can prime posts for likes or provide additional meta-information of value.

\subsubsection{Summary}

Combining all of these results (keeping in mind that $80 \%$ of all promotions happen before assignment deadline) - high quality posts get more promotions, the promotion hit rate is higher for quality content, and all types of promotions are useful - this means promotions are a powerful method for identifying quality material: students can successfully identify high quality content.

\subsection{Evaluation 3: Navigating Promotions}

On average, each post was read 22.9 times during the semester; gold star posts were read, on average, 44 times. The promoted posts were, on average, of higher quality, but were the students guided by the promotions to read those posts more frequently than the average post? Posts without any promotion feedback were read 16.8 times. Promoted posts got 33.5 reads - twice as many! Not only are students promoting quality content but they also act on the promotions. The community as a whole steers itself towards quality content using the promotions feature.

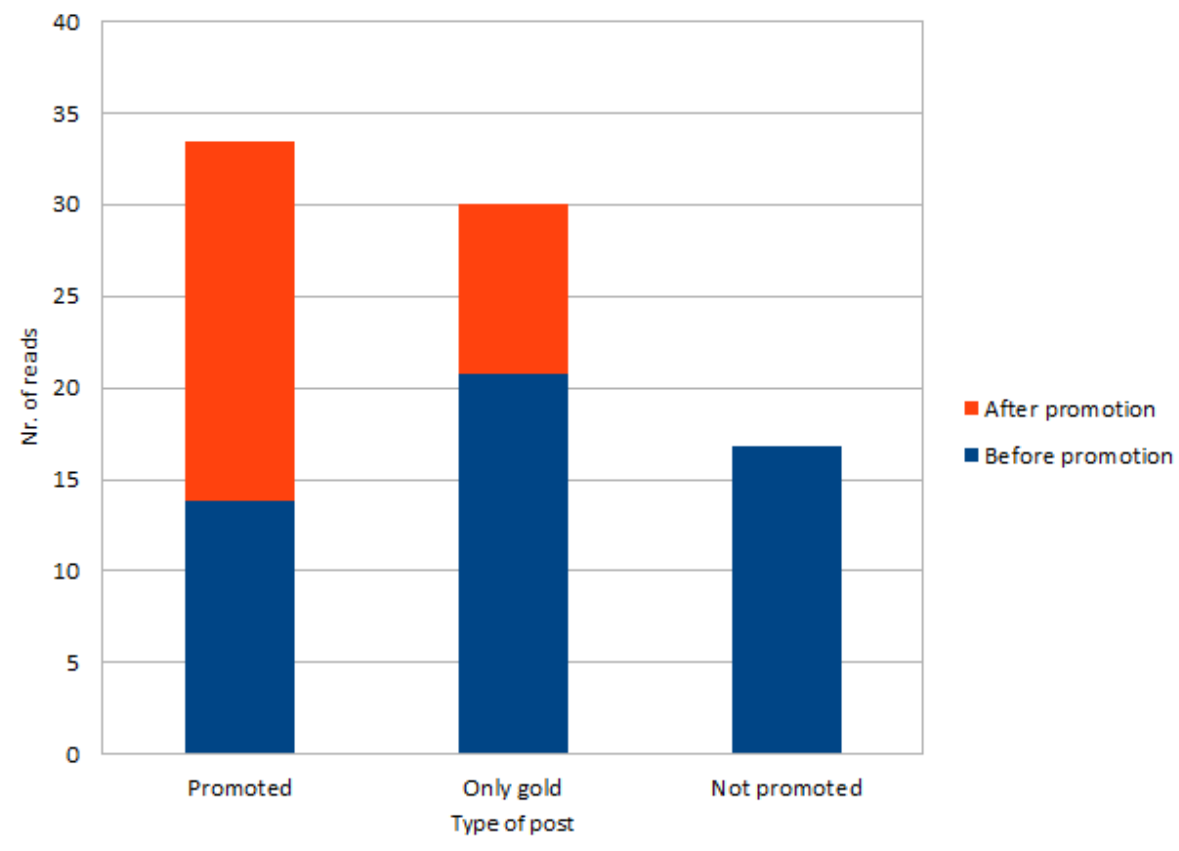

Figure 4. Average number of reads before and after promotion.

Some posts only get likes, some posts only get badges, other posts ( 25 out of 80 total gold stars) get only gold stars, and finally many posts get no promotions or gold stars. All posts get about the same average number of reads ( 15) before any promotions or gold stars. After a post gets a promotion its' exposure is greatly increased and it accrues a lot more reads from students (see Figure 4). Gold stars are given after the deadline, shortly after grading (usually about a week or two after deadline), and do increase the number of reads a post receives. Why a gold star only post has more reads before it gets a gold star is interesting, a possible reason is because they are cited in other students' posts (see cross-links below). 
(2014). Peer Promotions as a Method to Identify Quality Content. Journal of Learning Analytics, 1(2), 126-150.

These posts also get fewer average reads than promoted posts but that is most likely because gold stars are awarded later.

How students use promotions can be seen in students' cross-links (links to other students' posts within their own post). On average a cross-linked post has 1.93 promotions whereas a post that was not crosslinked only has 0.88 promotions, on average. The quality, measured by grade, of the cross-linked posts is also significantly higher ( $p$-value $=4.778 \mathrm{e}-12$ ). Students clearly use the promotions to navigate and use them as a source to improve their own work.

\subsection{Evaluation 4: Promotion Predictions}

Are some students better at promoting quality material than others? We wanted to know which students were reliable: both among students who consistently promoted high quality content and students who tended to promote poor content. Figure 5 shows that some students promote high quality posts, other students mostly promote low quality posts, but the majority of students are less predictable. A third (33) of the students regularly promote posts (5 or more assignments); a quarter (23) of all students consistently promote high quality posts (labelled good promoters in Figure 5). Out of those 23, seven students are also regular promoters, averaging 16.7 promotions throughout all assignments.

In Figure 5, good promoters refers to students who on average promoted posts that received a good grade (on or above the top line), and poor promoters are the students who promoted posts that received a poor grade (on or below the bottom line). Obviously, the posts promoted by students who reliably promote high quality material can be used to feature content in the blogosphere. In terms of assessment, the users classified as poor promoters present an interesting case. First of all, getting them to stop promoting content will immediately increase the average quality of promoted content. Secondly, this information can be used by the instructor as a teaching opportunity - these users lack an important critical reading skill.

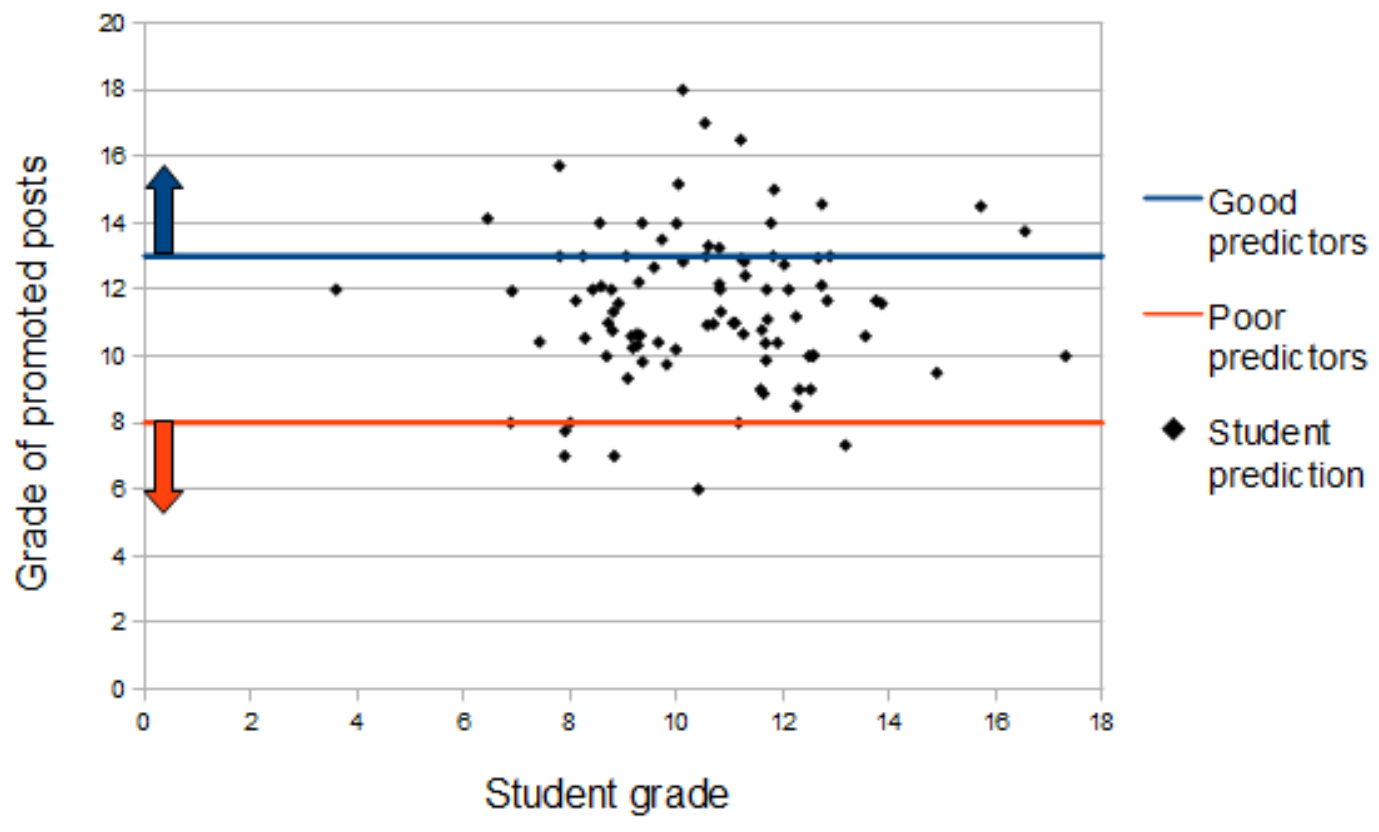

Figure 5. Average grades vs. average promoted grades 
The distribution is interesting in that the grades of students and the grades of the posts they promote do not correlate. One might expect that students who produce high quality content to be the same ones who can identify quality content by promoting. However, some students who get high grades only promote average or low quality content. Perhaps, even more surprisingly, there are students who receive low grades on the posts they produce but are very good at identifying and promoting high quality content. This suggests that students are developing two different skills (that could be classified by drawing a line up and along the average grade (10.7) on both axes): 1) writing and 2) identifying quality content. A student can be good at both, either, or neither. One of the benefits of the promotion data for instructors is that it can be used to measure the writing and critical reading abilities of each student. We consider this an important finding, one that can make promotions a very useful feature in educational blogs.

\subsection{Evaluation 5: Promotions and Post Quality During the Semester}

The distribution of grades and accuracy of promotions did not stay the same throughout the semester. The number of good predictors increased slightly and the number of poor predictors decreased by more than half. At the same time, the number of poor quality posts decreased and the number of average posts increased. What this tells us is that the average quality of the content is increasing and that the students are becoming more accurate at promoting. Analysis of the data is not that conclusive though.

A three-factor ANOVA test of assignment number, likes, and badges indicated a negative trend in student promotions. While there was a slight increase in mean assignment grade over the course of the semester, it was not significant $(F=0.983$, $p$-value $=0.452)$. There was a high negative correlation in the difference of marginal means (Pearson correlation -0.8, p-value 0.005). This can be explained by the change in the distribution of grades (see Figure 6), making it more difficult to identify high quality posts.

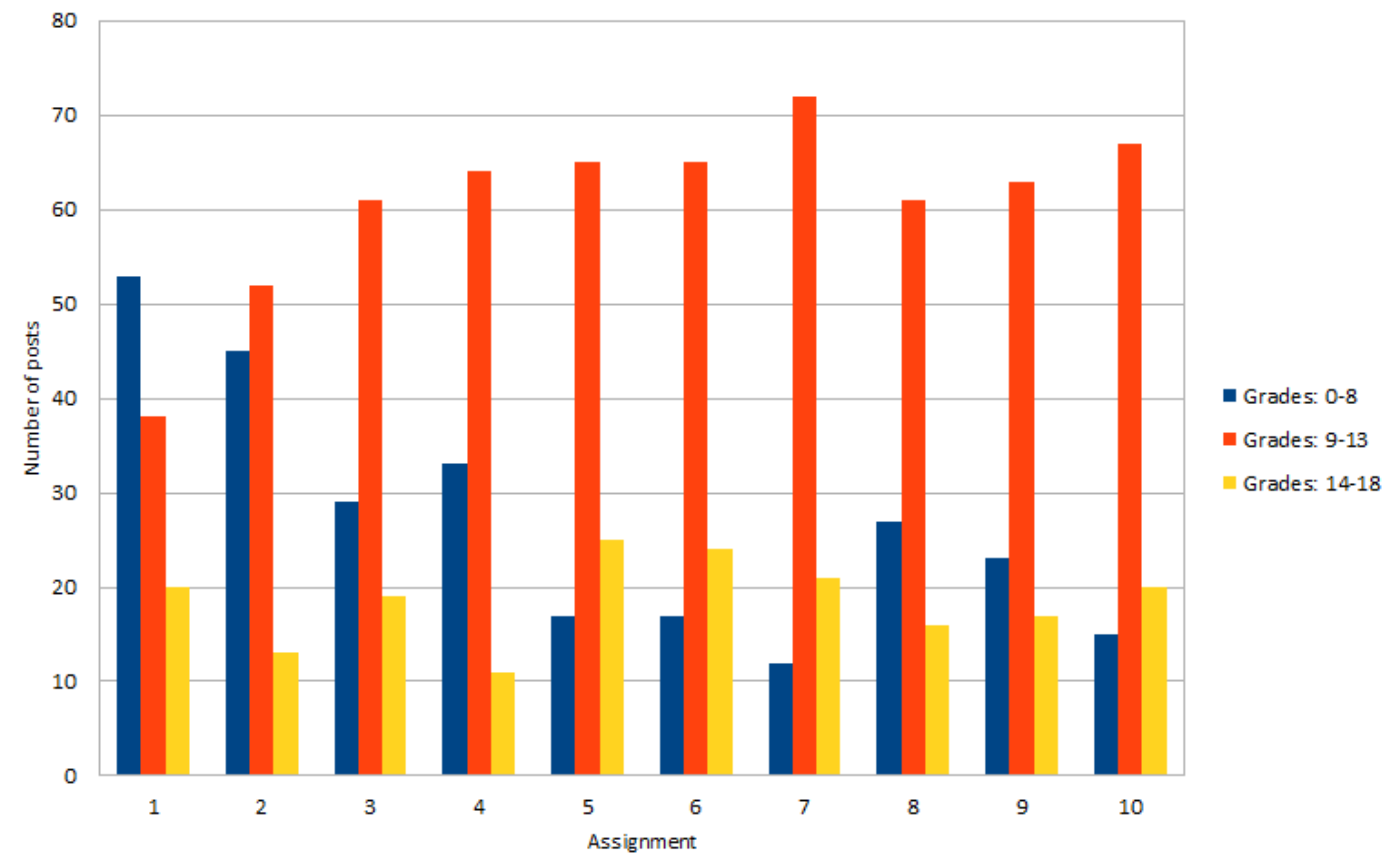

Figure 6. Number of posts per grade and assignment. 
(2014). Peer Promotions as a Method to Identify Quality Content. Journal of Learning Analytics, 1(2), 126-150.

Remember from the grading rubric, a grade of 12 was considered a good post; high quality posts are considered to "exceed expectations." During later assignments, having a much higher number of average quality posts compared to poor quality posts means that it is much harder to differentiate between high quality and poor quality. The main difference between the group of students who promote high quality and poor quality is the reliability of good promoters. Figure 7 shows the number of people who could be called "consistent promoters"; at least half of their promotions were either of high quality or poor quality.

Predictors per assignment

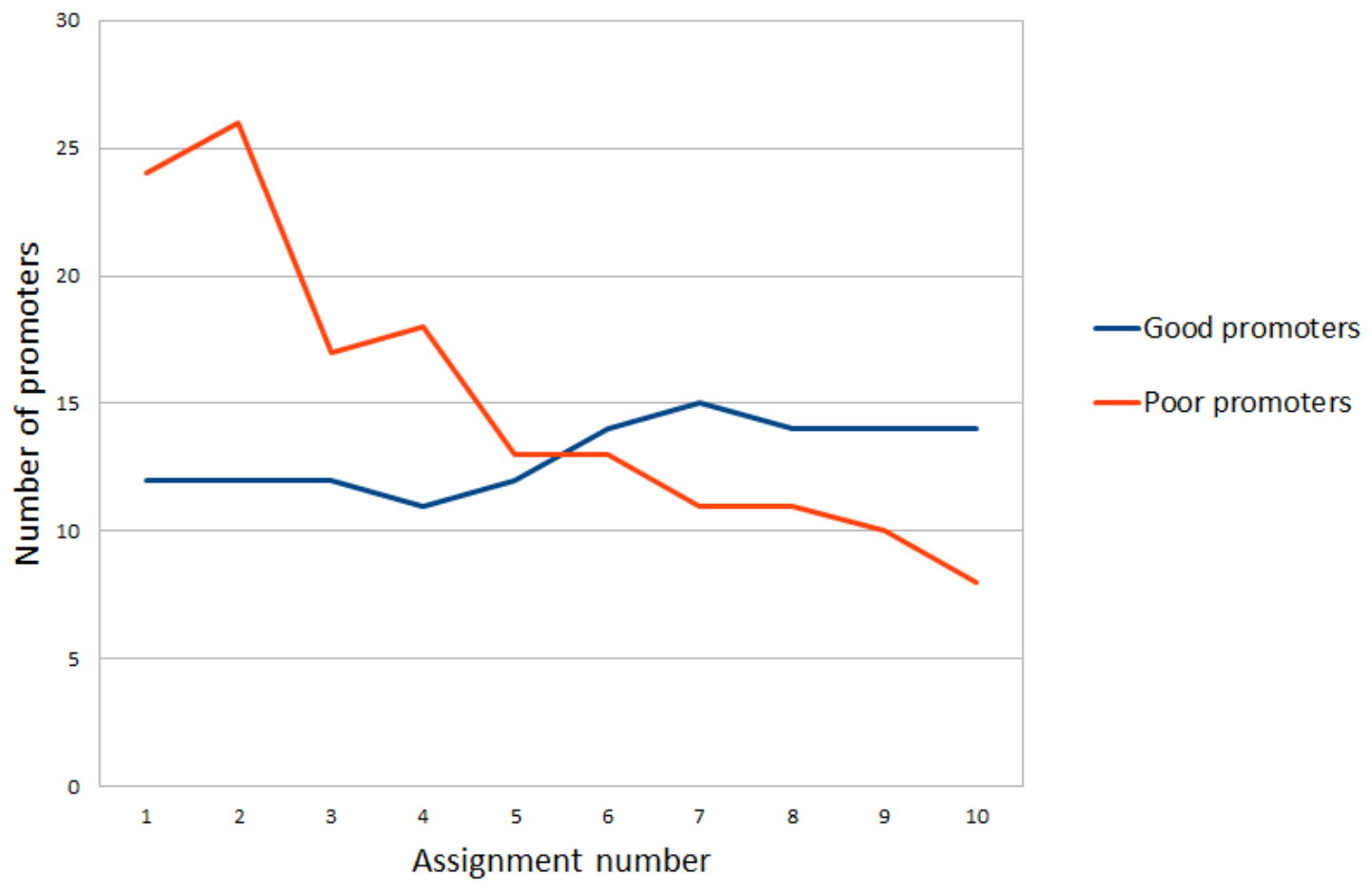

Figure 7. Number of consistent promoters.

Ideally, students improve their promotion skills over time, meaning that as the semester progresses students become even more accurate at identifying high quality content. Unfortunately, the results are mixed for this claim. The number of promotions went down over the semester while the overall quality of content went up. Students became less accurate with their promotions but their hit rate was slightly better.

There was considerably less poor content in later assignments and fewer students consistently giving poor promotions. However, the number of high quality posts was about the same as poor quality posts in later assignments, yet the number of reliably good promoters remained steady and exceeded the number of people who promoted poor posts in later assignments, even though the number of good and poor posts was about the same. This is an echo of the hit rate in evaluation 2: higher quality content has a higher promotion hit rate than lower quality content. 
In an environment of contrasting content, in terms of quality, differentiation is easy. Exploring the hit rate between assignments provides an insight. During the promotion-stable part of the semester (assignments 2 through 9), there was a noticeable drop in the promotion hit rate for poor and average quality posts between the first half of the assignments and the second half. The poor quality hit rate dropped from $\sim 35 \%$ to $\sim 30 \%$ and the average quality hit rate dropped from $\sim 50 \%$ to just below $45 \%$. The high quality hit rate was the same at around $56 \%$. While the overall quality of content improved, the hit rate of lower quality posts declined.

Early in the semester, the difference between high quality posts and poor quality posts was much larger than later in the semester. Notice in Figure 6, because of the pattern of assignment (editorial, review, editorial, review, et cetera), the improvement began to emerge with the second assignment of each type. With the overall improvement in the quality of posts, the discrimination between high quality and poor quality becomes more difficult to make, but also less significant; in other words, the average promoted post was always of higher quality than one that was not promoted. The change in overall quality is a good thing for the students, because reading better material is more productive. The goal of having students read better content is achieved with the overall improvement in content and by providing a smaller subset of higher quality posts through the promotion feature.

\subsection{Summary of Analysis}

Evaluation 1. Students promote posts as they read in the blogosphere.

Evaluation 2. Students accurately identify high quality content.

Evaluation 3. Students use promotions to navigate.

Evaluation 4. Students can be classified by the content they promote.

Evaluation 5. As the semester progresses, students have access to better content.

So, does this mean that the promotion activity identifies high quality with minimal instructor involvement? Because students actively promote, because the promotions are useful, and because we can identify good predictors and poor predictors, high quality content can be predicted based on who promotes it. Yes, the content students promote is of considerably higher quality than posts not promoted. In addition, the analysis provides hints that the promotion feature can, to some extent, be used to measure a student's critical reading and writing skills.

\section{CASE STUDY TWO: WEEKLY ASSIGNMENTS IN A HUMAN COMPUTER INTERACTION COURSE}

Data from another case study confirms some of the results of the initial study concerning the quality of promotions; that students actively use promotions and that they accurately identify high quality content.

The basis of the second study was a course on Human Computer Interaction $(\mathrm{HCl})$ taught in a Computer Science department and cross listed in Psychology (Alterman \& Gunnarsson, 2013). There was a mix of 50 undergraduate and master's students in the course, with weekly homework assignments. Homework was done in a blogging environment. The weekly assignments were blog posts where students either implemented or applied $\mathrm{HCl}$ techniques to various assignments. Each week there was an assignment deadline and a comment deadline. Students could, at any time, read, comment, and give likes. For this class, there were no merit badges. 
Students were free to post drafts of their homework before the deadline, read each other's drafts, and revise their assignments up until the deadline. After the completion of each assignment, there was an official three-day commenting period; students were required to post substantial comments on the randomly assigned posts of two other students. As the semester progressed, some of the earlier work of the students became relevant to the term project. Thus students were to free browse, comment, and like the work of other students. The data shows that many students actively read in the blogosphere throughout the semester (Alterman \& Gunnarsson, 2013); they regularly read each other's posts while working on each assignment and continued to read them after the completion of each assignment. The term project was purposefully designed in such a way that the content created in previous assignments could be used as source material. While writing the term project, students frequently browsed previous posts.

The same blogging environment was used in both classes, the I\&S class had been upgraded to use badges and some minor $\mathrm{UI}$ (user interface) changes had been made. For the $\mathrm{HCl}$ class, the front page listed the most recent posts in reverse chronological order. The students could filter the posts by assignment, by author, or by using a search mechanism. Regardless of how the posts were filtered, the list of posts generated was always in order of the most recent, with each post summary including a count of the number of likes and comments. The content of a post could be previewed by hovering with the mouse over the title.

Grading of posts and comments was done by three graduate students. The grading scheme was simpler than that employed for the I\&S class. Where for the I\&S course the parts of the post were graded, for this class a single grade, on the scale of $0-3$ was given to each assignment:

- 0 means that part was "not completed"

- 1 means "not good"

- 2 means "good work"

- 3 means "exceeds expectations"

Comments were graded on the 0-2 scale where the numbers meant the same as for post grades but comments could not exceed expectations. Each post was graded by a single grader; posts were randomly assigned to each grader for each assignment. The instructor and the graders had weekly meetings, before the grading for an assignment began. During the meeting, several assignments were graded collectively to coordinate the grading rubric for the assignment.

Students actively used the promotion feature; the average quality of liked posts was higher than posts that were not promoted (see Figure 8 , which shows grades scaled between 0 and 1 ).

Table 1 compares some of the key numbers in this second study to those in the I\&S study. The students in the I\&S class did more promoting, but those promotions also include badges; liking an entire post is a more stringent criteria than liking some feature of the post, for example, if it had "good references." While a student might not be ready to give a post a like, she might consider giving the post a badge. For both classes, high quality material was more likely to be promoted than poor quality material, as measured by the hit rate. Some differences between hit rate numbers are undoubtedly a result of the difference between the grading and promotion schemes in the two classes. To repeat: in the $\mathrm{HCl}$ study, students could only "like," there were no merit badges, and grades were on a simpler scale, from 0 to 3. The merit badges in the I\&S course were less accurate predictors of high quality content than the likes 
(2014). Peer Promotions as a Method to Identify Quality Content. Journal of Learning Analytics, 1(2), 126-150.

but they do contribute to a greater hit rate of high quality content. The simpler grading scheme and the lack of merit badges probably explain the lower hit rate of poor quality posts in the $\mathrm{HCl}$ class data set. So while the high quality hit rate in the $\mathrm{HCl}$ study might not look as impressive as in the I\&S one, the low poor quality hit rate is impressive - it makes the subset of promoted posts less "polluted" by poor quality content than the promoted I\&S content.

Average grade difference

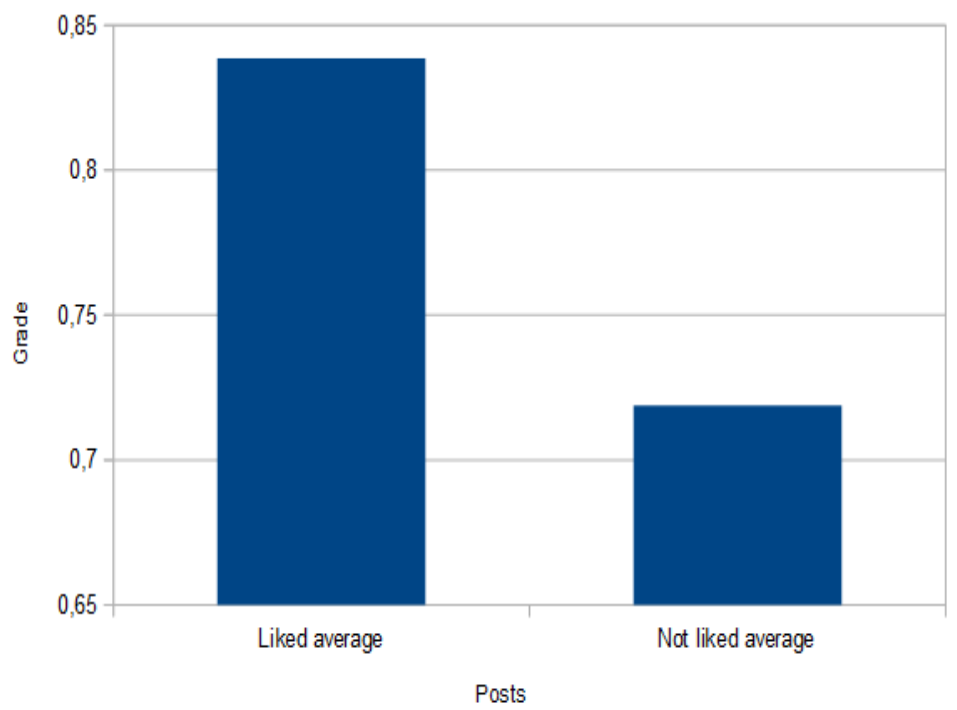

Figure 8. Difference between the average grade of posts that were "liked" and those that were not. Grades are scaled between 0 and 1.

Table 1. Comparing data from the two case studies.

\begin{tabular}{|l|c|c|}
\hline & I\&S & HCI \\
\hline Promotions per user & 6.77 & 4.1 \\
\hline High quality hit rate & $54.3 \%$ & $45.5 \%$ \\
\hline Poor quality hit rate & $36.2 \%$ & $18 \%$ \\
\hline
\end{tabular}

To summarize, the data from the second case study confirms some of the key results of the I\&S case study:

1. The students actively promoted content throughout the semester.

2. The promoted posts were, on average, of higher quality than the posts that were not promoted.

3. High quality content was more likely to be promoted and thus had a higher hit rate. 


\section{DISCUSSION}

In our class, students get feedback through grades, comments, peer assessments, and promotions. Future work will evaluate the effectiveness of the promotion activity without the rigorous grading done in this class. If instructors were to grade fewer posts, would student promotion improve over the course of the semester as the data has shown? What if the only posts graded were the promoted ones?

Consider, as a possible grading scheme, for the instructor to grade only promoted posts. This reduces work for the instructor. Under this grading scheme, it would be possible to ascertain which students are good predictors, which students are less predictable, and which students do not participate. This level of effort on the instructor's part is sufficient to develop some kind of highlighting mechanism, possibly a replacement for the gold star feature. The obvious downside of this scheme is that some students would not be receiving feedback or grades from the instructor (or the graders). If needed, posts that were never promoted could be randomly sampled for grading purposes. With this additional work, the instructor would be able to monitor the progress of students from assignment to assignment, both as readers and contributors. Regarding feedback, students would be receiving regular feedback from the instructor (but not every week). They would also be receiving peer feedback in the form of comments and promotions, and have access to highlighted content to compare to their own work or to build upon. With this scheme, some of the posts that were not promoted but were of high quality would be discovered.

In a blogosphere, as a learning environment without the promotions described in this article, there is a possible bias for work posted either early or late. Do early posts garner disproportionately more attention and feedback? Do poor quality early posts have a negative impact on the discussion? Do later contributions suffer from the opposite problem: too little feedback and promotions from peers? Is the peer assessment requirement the driving force of promotions, without which there wouldn't be many promotions? The hope is that the quality of contributions gradually increases towards the due date as students read and update previous contributions based on more recent and collected content, and that the early post bias does not slow down this progress.

The blogosphere, with the promotions described in this article, potentially compounds the early and late bias. Based on the results, the promotions may have a positive impact on the early post bias by identifying the high quality early posts, hinting that those not promoted may need updating. In the early bias case, promotions may be the solution. The problem in the other direction - overlooking good quality posts contributed late - may require some scheming to remedy. One possibility is to leverage the random assignment of required commenting. During the commenting period students can, and do, promote content. If these late promotions are made by good promoters then they become prime candidates for further review as gold star contributions. But in either direction, the question of bias requires further study.

Suppose the blogosphere has only a few users that produce little content. Would promotions work differently with this number of students versus this content-amount dynamic? Since there is so little content, students who want to collaborate or need help can just read everything. Also, would a more intimate setting of only a few users trigger everyone to promote everything? In this case, the promotions are working differently as mostly a positive feedback mechanism supporting student engagement. 
One part of the class was peer assessments. Generally, students did not give likes to the posts they were assigned to assess (only 10 likes from seven students); students were more likely, however, to give badges during assessments (58 different students on 213 occasions giving badges to 196 different posts). This amounts to just fewer than $6 \%$ of all likes and $21 \%$ of all badges awarded. Students only awarded a post with a promotion if they had assessed it to be of high quality; however, a brief exploration of the peer assessments indicated that they were not reliable. The interaction between peer assessments and promotions could be a topic of another analysis. For this article, assessments may have had a negative impact on the quality of badges, the difference in average grade between badges awarded during assessment and those awarded at other times was significant ( $p$-value $=0.02434)$. The difference in means, while statistical, is only half a grade point. We cannot conclude that, without the assessments, badges would have been of a higher quality.

While badges do not add much statistical value to likes, they are numerous and as such of social value. Would likes be as predictive, for example, without badges? The difference in grade schemes in the $\mathrm{HCl}$ and I\&S courses makes it difficult to say. The badges may add a level of assessment between a like and no like, thus making the difference between a like and no like greater than it would be without badges.

Do these results generalize beyond blogging? Suppose the students are tweeting (many contributions from either many or a few students). Does the notion of promoting make sense under these conditions? Perhaps, but for this kind of learning activity the middle space would be somewhat different, and consequently the analytics would clearly have to be adjusted. For various kinds of loosely coordinated learning activities, promotions hold promise, but the devil is in the details. Whether and how to convert the promotions into assessment and feedback would necessitate further study.

Overall, the results of this research are very promising but we do not assume that the promotion feature can be automatically applied to any learning environment and be a success, as explained by the middle space. However, the possibilities the promotion feature enables for learning analytics are of interest.

\section{CONCLUSION}

In this article we have explored the use of peer promotions as a tool to filter for high quality content. The data shows that students willingly use the tool and that the application of the tool provides the desired results - the promoted content is of significantly higher quality than content that is not promoted, and content that is repeatedly promoted is of higher quality than content that has fewer promotions. These results have been verified by two different case studies. Other results show that good and poor promoters can be identified. Both classifications of promoters have value: by focusing on good promoters, the reliability of quality assessment can be improved; by focusing on poor promoters, the instructor is in a better position to identify students who may be struggling.

Navigating a huge amount of peer-generated content in a knowledge community on a weekly basis is a lot of work. Not all content is of sufficient quality to be considered useful for all students. Being able to filter the content for quality would be invaluable. The social activity of promoting each other's material, if properly applied, enables students collectively to identify content that is interesting or of particular value. What the number of promotions might mean for a post will vary from one setting to another, but the promotion feature will always have social value. 


\section{REFERENCES}

Ainsworth, S. (2006). DeFT: A conceptual framework for considering learning with multiple representations. Learning and Instruction, 16(3), 183-198.

Alterman, R., \& Gunnarsson, B. (2013). The blogosphere as representational space. CSCL 2013 Conference Proceedings Volume 1: Full Papers \& Symposia, pp. 26-33. International Society of the Learning Sciences.

Alterman, R., \& Larusson, J. A. (2013). Participation and common knowledge in a case study of student blogging. International Journal of Computer-Supported Collaborative Learning, 8(2), 149-187. doi:10.1007/s11412-013-9167-2

Arnold, K. E. (2010). Signals: Applying academic analytics. Educause Quarterly, 33(1), n1.

Baker, M., Hansen, T., Joiner, R., \& Traum, D. (1999). The role of grounding in collaborative learning tasks. Collaborative learning: Cognitive and computational approaches, 31-63. Oxford, UK: Pergamon, Elsevier Science, 1999.

Benkler, Y., \& Nissenbaum, H. (2006). Commons-based peer production and virtue. Journal of Political Philosophy, 14(4), 394-419. doi:10.1111/j.1467-9760.2006.00235.x

Berners-Lee, T. (1989). Information management: A proposal. Retrieved 9 June 2014 from http://www.w3.org/History/1989/proposal.html

Bruckman, A. (1998). Community support for constructionist learning. Computer Supported Cooperative Work (CSCW), 7(1-2), 47-86. doi: 10.1023/A:1008684120893

Dawson, S. (2009). "Seeing" the learning community: An exploration of the development of a resource for monitoring online student networking. British Journal of Educational Technology, 41(5), 736752.

Deng, L., \& Yuen, A. H. K. (2011). Towards a framework for educational affordances of blogs. Computers \& Education, 56(2), 441-451.

Divitini, M., Haugalokken, O., \& Morken, E. M. (2005). Blog to support learning in the field: Lessons learned from a fiasco. Fifth IEEE International Conference on Advanced Learning Technologies ICALT, 5-8 July 2005, Kaohsiung, Taiwan.

Du, H. S., \& Wagner, C. (2006). Weblog success: Exploring the role of technology. International Journal of Human-Computer Studies, 64(9), 789-798.

Ducate, L. C., \& Lomicka, L. L. (2005). Exploring the blogosphere: Use of web logs in the foreign language classroom. Foreign Language Annals, 38(3), 410-421.

Ellison, N., \& Wu, Y. (2008). Blogging in the classroom: A preliminary exploration of student attitudes and impact on comprehension. Journal of Educational Multimedia and Hypermedia, 17(1), 99-122.

Ferdig, R. E., \& Trammell, K. D. (2004). Content delivery in the "blogosphere." T.H.E. Journal, 31(7), 1220.

Ferguson, R., \& Buckingham Shum, S. (2012). Social learning analytics: Five approaches. Proceedings of the 2nd International Conference on Learning Analytics and Knowledge, 29 April-2 May 2012, Vancouver, BC, Canada. New York: ACM Press. doi:10.1145/2330601.2330665.

Ferguson, R., Buckingham Shum, S., \& Deakin Crick, R. (2011, December 14). EnquiryBlogger: Using widgets to support awareness and reflection in a PLE Setting. In W. Reinhardt \& T. D. Ullmann (Eds.), Proceedings of the 1st Workshop on Awareness and Reflection in Personal Learning Environments, 11 July 2011. Southampton, UK. In conjunction with the PLE (Personal Learning Environment) Conference 2011. Retrieved from http://oro.open.ac.uk/30598/1/arple2011_(006904v1).pdf 
(2014). Peer Promotions as a Method to Identify Quality Content. Journal of Learning Analytics, 1(2), 126-150.

Gunnarsson, B. L., \& Alterman, R. (2012). Predicting failure. Proceedings of the 2nd International Conference on Learning Analytics and Knowledge: LAK '12 (p. 263), 29 April-2 May 2012, Vancouver, BC, Canada. New York: ACM Press. doi:10.1145/2330601.2330665.

Hong, W. (2008). Exploring educational use of blogs in us education. US-China Education Review, 5, 3438.

Huang, T. C., Cheng, S. C., \& Huang, Y. M. (2009). A blog article recommendation generating mechanism using an SBACPSO algorithm. Expert Systems with Applications, 36(7), 10,388-10,396.

Kargar, M. J., \& Azimzadeh, F. (2009). A framework for ranking quality of information on a weblog. World Academy of Science, Engineering and Technology, 56, 690-695.

Kay, A. (1991). Computers, networks and education. Scientific American, 265(3), 138-148.

Krause, S. D. (2004). When blogging goes bad: A cautionary tale about blogs, email lists, discussion, and interaction. Kairos, 9(1). Retrieved 9 June 2014 from http://english.ttu.edu/kairos/9.1/praxis/krause/

Luehmann, A. L. (2008). Using blogging in support of teacher professional identity development: A case study. The Journal of the Learning Sciences, 17(3), 287-337.

Luehmann, A., \& MacBride, R. (2009). Classroom blogging in the service of student-centered pedagogy: Two high school teachers' use of blogs. THEN: Technology, Humanities, Education, \& Narrative, 6, 5-36.

Lü, L., Medo, M., Yeung, C. H., Zhang, Y. C., Zhang, Z. K., \& Zhou, T. (2012). Recommender systems. Physics Reports, 519(1), 1-49.

Nardi, B. A., Schiano, D. J., Gumbrecht, M., \& Swartz, L. (2004). Why we blog. Communications of the $A C M, 47(12), 41-46$.

$\mathrm{Ni}$, X., Xue, G. R., Ling, X., Yu, Y., \& Yang, Q. (2007). Exploring in the weblog space by detecting informative and affective articles. Proceedings of the 16th International Conference on World Wide Web, 8-12 May 2007, Banff, AB, Canada.

O'Reilly, T. (2007). What is Web 2.0: Design patterns and business models for the next generation of software. Communications \& Strategies, 1, 17.

Philip, R., \& Nicholls, J. (2009). Group blogs: Documenting collaborative drama processes. Australasian Journal of Educational Technology, 25(5), 683-699.

Rubin, V. L., \& Liddy, E. D. (2006). Assessing credibility of weblogs. Proceedings of the AAAl Spring Symposium: Computational Approaches to Analyzing Weblogs (CAAW), 27-29 March 2006, Stanford University, CA, USA.

Scardamalia, M., \& Bereiter, C. (1994). Computer support for knowledge-building communities. The Journal of the Learning Sciences, 3(3), 265-283.

Scardamalia, M., \& Bereiter, C. (2006). Knowledge building: Theory, pedagogy, and technology. In R. K. Sawyer (Ed.), The Cambridge handbook of the learning sciences (pp. 97-115). Cambridge, UK: Cambridge University Press.

Scardamalia, M., Bransford, J., Kozma, B., \& Quellmalz, E. (2012). New assessments and environments for knowledge building. Assessment and Teaching of 21st Century Skills, 231-300. Netherlands: Springer. doi 10.1007/978-94-007-2324-5_5

Siemens, G. (2011). Learning analytics: A foundation for informed change in Higher Education. http://www.educause.edu/library/resources/learning-analytics-foundation-informed-changehigher-education

Smolin, D., \& Butakov, S. (2012, April). Applying artificial intelligence to the educational data: An example of syllabus quality analysis. Proceedings of the 2nd International Conference on Learning Analytics and Knowledge (pp. 164-169). New York: ACM Press. 
(2014). Peer Promotions as a Method to Identify Quality Content. Journal of Learning Analytics, 1(2), 126-150.

Stahl, G. (2003). Meaning and interpretation in collaboration. Designing for change in networked learning environments: Proceedings of the International Conference on Computer Support for Collaborative Learning (CSCL'03). Bergen, Norway

Stahl, G. (Ed.). (2009). Studying virtual math teams. New York: Springer.

Stahl, G., Koschmann, T., \& Suthers, D. (2006). Computer-supported collaborative learning: An historical perspective. In R. K. Sawyer (Ed.), The Cambridge handbook of the learning sciences (pp. 409426). Cambridge, UK: Cambridge University Press.

Suthers, D. (2006). Technology affordances for intersubjective meaning making: A research agenda for CSCL. International Journal of Computer-Supported Collaborative Learning, 1(3), 315-337. doi:10.1007/s11412-006-9660-y

Suthers, D., \& Verbert, K. (2013). Learning analytics as a "middle space." Proceedings of the Third International Conference on Learning Analytics and Knowledge - LAK'13 (p. 1). New York: ACM Press. doi:10.1145/2460296.2460298

Topping, K. (2005). Trends in peer learning. Educational Psychology, 25(6), 631-645. doi:10.1080/01443410500345172

Ulicny, B., Baclawski, K., \& Magnus, A. (2007). New metrics for blog mining. Data Mining, Intrusion Detection, Information Assurance, and Data Networks Security 2007; SPIE Volume 6570, 65700I, 9 April 2007. Orlando, FL, USA.

Wang, K. T., Huang, Y.-M., Jeng, Y.-L., \& Wang, T.-I. (2008). A blog-based dynamic learning map. Computers \& Education, 51(1), 262-278. doi:10.1016/j.compedu.2007.06.005

Williams, J. B., \& Jacobs, J. (2004). AJET 20: Exploring the use of blogs as learning spaces in the higher education sector. Australasian Journal of Educational Technology, 20(2), 232-247.

Zagal, J. P., \& Bruckman, A. (2007). GameLog: Fostering reflective gameplaying for learning. Proceedings of the 2007 ACM SIGGRAPH Symposium on Video Games, 5-9 August 2007, San Diego, CA, USA. 